\title{
8-Chloro-cAMP-Related Changes on Mice Uteri
}

\author{
Andrea Actis ${ }^{1,2}$, Máximo Croci $^{3}$, Emanuel Levin ${ }^{1}$, and Rosa Bergoc ${ }^{4, *}$ \\ ${ }^{1}$ Department of Human Biochemistry, School of Medicine, University of Buenos Aires, \\ Buenos Aires, Argentina; ${ }^{2}$ Institute of Health Sciences, Foundation Barceló, Buenos \\ Aires, Argentina; ${ }^{3}$ Institute of Immunooncology Dr. J.V. Crescenti, Buenos Aires, \\ Argentina; ${ }^{4}$ Radioisotopes Laboratory, School of Pharmacy and Biochemistry, University \\ of Buenos Aires, Junin St. 956 (1113), Buenos Aires, Argentina \\ Email: andrea actis@hotmail.com; rmbergoc@ffyb.uba.ar
}

Received February 13, 2002; Revised March 24, 2002; March 26, 2002; Published May 22, 2002

Histopathological effects of CAMP analog (8-Chloro-cAMP), tamoxifen, and medroxyprogesterone, alone or combined, upon BALB/c mice uteri are reported. 8Chloro-cAMP diminished uterine weight, but did not modify its histopathology or estral cycle significantly. Tamoxifen diminished uterine weight showing cystic hyperplasia and an estral cycle arrested at diestrus. Medroxyprogesterone increased uterine weight, caused a swelling of the endometrium and a pseudopregnancy estrus. When combined with 8-Chloro-cAMP, tamoxifen or medroxyprogesterone always had a predominant effect. We concluded that the effects of 8-Chloro-cAMP on mice uteri did not cause significant changes on its histopathology, but diminished its weight.

KEY WORDS: 8-Chloro-cAMP, tamoxifen, medroxyprogesterone, mice, uterus, histopathology

DOMAINS: pharmaceutical sciences, cancer, endocrinology, pharmacology

\section{INTRODUCTION}

The study of 8-Chloro-cAMP pharmacological effects, alone or in combination with other compounds such as tamoxifen and medroxyprogesterone on a hormone-dependent tissue like the uterus, has two objectives: first, to explore how those pharmacological agents affect the cell development of a target tissue of estrogens and, second, to reveal the diverse protein-protein interactions by the different transductional pathways activated by each of them. In this work, we studied the effects of 8-Chloro-cAMP, alone or in combination with tamoxifen or medroxyprogesterone, on the histopa- 
thology of uterine mice. 8-Chloro-cAMP is a cAMP analog drug that binds to the regulatory subunit of cAMP-dependent protein kinase (PKA), as determined by Cho Chung[1]. PKA has two regulatory $(R)$ and two catalytic subunits. There are two kinds of $R$ subunits: $R_{I}$ and $R_{I I} \cdot R_{I}$ is related to the proliferative actions of $\mathrm{cAMP}$, and $\mathrm{R}_{\mathrm{II}}$ is related to the differentiation processes triggered by cAMP. 8-Chloro-cAMP binds preferentially to the $\mathrm{R}_{\mathrm{II}}$ subunit, and the antitumoral action is attributed to this binding[2]. It is known that cAMP induces an inhibitory effect on cell growth[3]. The antitumoral action of 8-Chloro-cAMP was investigated in several organs, such as the colon, in breast cell lines cultured in vitro [4], in nude mice[5,6,7], and using in vivo models[4]. These investigations determined that 8-Chloro-cAMP inhibits autocrine and angiogenic growth factor production in colorectal and breast cancer cells. Scala et al.[8] and other researchers[9] investigated the mechanism of the action of this drug. Currently, 8-Chloro-cAMP is being used as an anticancer drug in various treatment protocols[1,6,10]. Medroxyprogesterone is a synthetic progesterone-analog and, as such, binds to progesterone receptor (PR) molecules. As indicated by Panutti et al.[11], it is used in mammary cancers to counteract estrogen action. In mice, Lanari et al.[12] and Molinolo et al.[13] showed that medroxyprogesterone was able to induce mammary carcinogenesis and accelerates tumor growth in the medroxyprogesterone-dependent tumors. Tamoxifen is a selective estrogen receptor modulator (SERM) widely utilized for breast cancer treatments as an antiestrogen, acting by different mechanisms but mainly through blocking estrogen receptor (ER) molecules[14,15]. In a previous report, we studied the effect of tamoxifen, medroxyprogesterone, and 8-Chloro-cAMP in ERs and PRs of BALB/c mice uteri[16,17]. Furthermore, we determined that 8-Chloro-cAMP and its association with medroxyprogesterone had a different effect on two mammary tumor sublines induced in BALB/c mice by medroxyprogesterone injection[18]. It was our aim to analyze the effect of 8-Chloro-cAMP, alone or in combination, with other antineoplastic agents on the histopathology of uterine tissue.

\section{EXPERIMENTAL MATERIALS AND PROCEDURES}

\section{Animals}

Female BALB/c mice 50-60 days old were employed. The animals were kept under the conditions recommended by the Guide of Care and Use of Laboratory Animals, U.S.

\section{In Vivo Treatments}

Animals were randomly divided into six groups of five mice per group. One group was used as the control group. These were treated with vehicle. Mice of the other five groups received different treatments initiated simultaneously. The 8-Chloro-cAMP group received a subcutaneous pellet (15 $\mathrm{mg} / \mathrm{kg}$ day); each pellet lasted 10 days and was changed successively. The medroxyprogesterone group received a subcutaneous drug depot $(0.25 \mathrm{mg} / \mathrm{kg}$ day $)$. The tamoxifen group was treated with a subcutaneous pellet $(0.25 \mathrm{mg} / \mathrm{kg}$ day); drug delivering from the pellets of tamoxifen and medroxyprogesterone lasted 2 months with a linear-type releasing kinetic. In combined treatments, doses of the combination of drugs utilized were the same as previously described. The selection of dose employed was based in previous results obtained from murine mammary tumors[17].

\section{Estrus Cycle and Uterine Weight Determination}

The estrus cycle was determined daily by vaginal smears. 


\section{Histopathology}

Representative samples of all uteri were harvested for histological examination.

\section{Reagents}

Gador S.A., Buenos Aires, Argentina, kindly provided tamoxifen and medroxyprogesterone. 8-chlorocAMP was a gift from Y.S. Cho Chung, M.D., National Cancer Institute, U.S.

\section{RESULTS}

\section{Uterine Weight}

The drugs tested in this study acted diversely on this parameter as is shown in Table 1. This table sums up quantitative data and each treatment's significance level.

\section{Estrus Cycle}

Table 2 shows the effects of drugs employed upon the estrus cycle.

\section{Histopathology}

Table 3 summarizes histopathological findings according to the different treatments. See Fig. 1.

TABLE 1

Changes in Uterine Weight According to Treatments

\begin{tabular}{lcc}
\hline Treatment & $\begin{array}{c}\text { Uterine Weight }(\mathbf{m g}) \\
\text { (Mean } \pm \text { SD) }\end{array}$ & $\boldsymbol{p}$ value \\
\hline Vehicle & $111.6 \pm 11.1$ & - \\
8-Chloro-cAMP & $84.2 \pm 14.0^{*}$ & $<0.05$ \\
Tamoxifen & $62.6 \pm 10.1^{* \star *}$ & $<0.001$ \\
Medroxyprogesterone & $150.8 \pm 19.4^{* * *}$ & $<0.001$ \\
8-Chloro + tamoxifen & $62.6 \pm 3.4^{* * *}$ & $<0.001$ \\
8-Chloro + medroxyprogesterone & $137.6 \pm 6.3^{*}$ & $<0.05$ \\
\hline
\end{tabular}

TABLE 2

Changes in Estrus Cycle According to Treatments

\begin{tabular}{ll}
\hline Treatment & Estrus Phase \\
\hline Vehicle & Normal cycle (4 days) \\
8-Chloro-cAMP & Extended cycle duration (10 days) \\
Tamoxifen & Permanent diestrus \\
Medroxyprogesterone & Permanent pseudopregnancy aspect \\
8-Chloro + tamoxifen & Permanent diestrus \\
8-Chloro + medroxyprogesterone & Permanent pseudopregnancy \\
\hline
\end{tabular}


TABLE 3

Histopathological Findings According to Treatments

\begin{tabular}{llc}
\hline Treatment & Histopathological Findings & Figure \\
\hline Vehicle & Normal proliferative epithelium & 1a \\
& Scarce stroma & \\
& Lack of secretory glands & \\
8-Chloro-cAMP & Same as vehicle & $1 \mathrm{~b}$ \\
Tamoxifen & Cystic hyperplasia & $1 \mathrm{c}$ \\
& Hyperproliferative areas & \\
& Important mitotic activity & \\
Medroxyprogesterone & Scarce stroma & $1 \mathrm{~d}$ \\
& Progestational-like endometrium & \\
& Numerous glands with serrated & \\
8-Chloro + tamoxifen & appearance and secretory signs & $1 \mathrm{e}$ \\
8-Chloro + medroxyprogesterone & Same as tamoxifen & $1 \mathrm{f}$ \\
\hline
\end{tabular}

\section{DISCUSSION}

8-Chloro-cAMP is a cyclic-AMP analog directly involved in cell proliferation and neoplastic transformation that causes growth inhibition in a variety of human cancer cell types. It is also known that in vitro it inhibits the expression of autocrine and paracrine growth factors[19]. Recently, numerous researchers have investigated the possible dual anticancer mechanism of 8-Chloro-cAMP through inhibition of cell proliferation and induction of apoptosis[20,21,22,23]. In a previous study, we analyzed the action of 8-Chloro-cAMP, tamoxifen, and medroxyprogesterone, alone and in combination, upon the uteri of BALB/c mice[17]. We observed that 8-Chloro-cAMP and medroxyprogesterone did not modify significantly the content of estrogen receptors. In the current study, we found that 8-Chloro-cAMP did not overcome the effects seen in the treatment of mice with tamoxifen (weight loss, estral cycle arrested at diestrus phase, cystic hyperplasia, and mitogenic action) in the uterine tissue. In combination with medroxyprogesterone, the progestin aspect of the endometrium produced by medroxyprogesterone was not counteracted by 8-Chloro-cAMP, and the uterine weight was not increased either. The interrelations or cross talk between different transductional pathways, which regulate the expression of a gene, are affected by the use of drugs addressed to some of the components of those pathways. So, as a result of the cross talk, unexpected effects can be seen. 8Chloro-cAMP as well as tamoxifen and medroxyprogesterone act on diverse transductional pathways. The combined administration of these drugs allows studying the way by which the interactions between proteins (cross talk) are modified when drugs that act only through a way are given[17]. In this article, even if 8-Chloro-cAMP effects on the analyzed parameters are not quite noticeable at the level of dose employed, we cannot reject the possibility that these effects may appear at different doses. In the mouse uterus, we determined that 8-Chloro-cAMP caused modifications in subcellular content and distribution of estrogen receptors[17]. It is interesting to comment on the modifications caused by 8-Chloro-cAMP alone on the histology of uterus, like a lower number of proliferative glands and the prolonged estral cycle; moreover, this compound diminished significantly the uterine weight $(p<0.05)$. These modifications could be signaling that by binding itself to the subunit $\mathrm{R}_{\mathrm{II}}$ of PKA, 8-Chloro-cAMP is able to favor differentiation and to diminish proliferation. 



FIGURE 1. Endometrium slice of mouse uterus under different treatments. 1a: Vehicle; proliferative endometrial glands with normal number of mitoses and absence of secretory changes. Dense stroma. 1b: 8-Chloro-cAMP; proliferative endometrial glands with scarce number and scarce stroma. 1c: Tamoxifen; quistic endometrial hyperplasia with secretory apical mucosal sectors and multistratification; mitotic figures were seen. 1d: 8-Chloro-cAMP + tamoxifen; proliferative endometrial mucosae with multistratificated nucleous, mitoses and cystic glands. 1e: Medroxyprogesterone; highly indented endometrial glands with marked serrated appearance; secretory vacuole located in the basal portion of the cylindrical epithelium. Clear edematous and scarcely cellular stroma between glands. 1f: 8-Chloro-cAMP + medroxyprogesterone; important number of secretory glands with serrated appearance, scarce apical secretion, and edematous stroma. In all cases, HE 100X.

\section{CONCLUSION}

The beneficial effects of estrogens in females are well known. However, these sexual hormones can trigger the proliferation of cells that will grow as a tumor, especially for breast cells. The first-line treatment for breast cancer that expresses estrogen receptors is tamoxifen. But this SERM, which exhibits estrogen receptor antagonism in breast cells, also presents agonist activity in the uterus. On the other hand, 8-Chloro-cAMP is able to reduce proliferation and favors differentiation acting 
through $\mathrm{R}_{\mathrm{II}}$ subunit of PKA. The evidence of cross talk between both biochemical pathways is well documented. Whether the combined treatment of tamoxifen and 8-Chloro-cAMP can keep proliferative activity triggered by tamoxifen under control remains to be determined.

\section{ACKNOWLEDGMENTS}

This work was supported by grants from Buenos Aires University (TB069) and from the National Agency of Scientific and Technological Promotion (PICT 04656). The authors acknowledge the technical assistance of Inés Nievas (CONICET).

\section{REFERENCES}

1. Cho Chung, Y.S. (1990) Role of cyclic AMP receptor proteins in growth, differentiation and suppression of malignancy: new approaches to therapy. Cancer Res. 50, 7093-7095.

2. Tagliaferri, P., Katsaros, D., Clair, T., Ally, S., Tortora, G., Neckers, L., Rubalcava, B., Parandoosh, Z., Chang, Y.A., Revankar, G., Crabtree, G.W., Robins, R.K., and Cho-Chung, Y.S. (1988) Synergistic inhibition of growth of breast and colon human cancer cell lines by site selective cyclic AMP analogues. Cancer Res. 48, 1642-1650.

3. Cho Chung, Y.S., Clair, T., Tortora, G., and Yokosaki, H. (1991) Role of site-selective cAMP analogue in the control and reversal of malignancy. Pharmacol. Ther. 50, 1-33.

4. Bianco, C., Tortora, G., Baldassarre, G., Caputo, R., Fontanini, G., Chin, S., Bianco, A.R., and Ciardello, F. (1997) 8-Chloro cyclic AMP inhibits autocrine and angiogenic growth factor production in human colorectal and breast cancer. Clin. Cancer Res. 3, 439-448.

5. Carlson, C.C., Chinery, R., Burnham, L.L., and Dramsfield, D.T. (2000) 8-Cl-adenosine-induced inhibition of colorectal cancer growth in vitro and in vivo. Neoplasia 2(5), 441-448.

6. Cummings, J., Langdon, S.P., Ritchie, A.A., Burns, D.J., Mackay, J., Stockman, P., Leonard, R.C., and Miller, W.R. (1996) Phamacokinetics, metabolism and tumour disposition of 8-chloroadenosine 3', 5'-monophosphate in breast cancer patients and xenograft bearing mice. Ann. Oncol. 7, 291-296.

7. Vincentini, G.E., Constantin, J., Lopez, C.H., and Bracht, A. (2000) Transport of cyclic AMP and synthetic analogues in the perfused rat liver. Biochem. Pharmacol. 59(10), 1187-1201.

8. Scala, S., Budillon, A., Zhan, Z., Cho-Chung, Y.S., Jefferson, J., Tsokos, M., and Bates, S.E. (1995) Down-regulation of mdr-1 expression by 8-Cl-cAMP in multidrug resistant MCF-7 human breast cancer cells. J. Clin. Invest. 96(2), 1026-1034.

9. Ciardello, F., Dixit, M., di Isernia, G., Damiano, V., Bianco, R., Bianco, A.R., Arteaga, C.L., and Tortora, G. (1998) Down-regulation of type I protein kinase A by transfection of human breast cancer cells with an epidermal growth receptor antisense expression vector. Breast Cancer Res. Treat. 47, 57-62.

10. Propper, D.J., Saunders, M.P., Salisbury, A.J., Long, L.O., Byrne, K.J., Braybrooke, J.P., Dowsett, M., Taylor, M., Talbot, D.C., Ganesan, T.S., and Harris, A.L. (1999) Phase I study of the novel cyclic AMP (cAMP) analogue 8chloro-cAMP in patients with cancer: toxicity, hormonal and immunological effects. Clin. Cancer Res. 5(7), 16821689.

11. Panutti, F., Martoni, A., Zaniagni, C., and Melotti, B. (1993) Progestins I: medroxyprogesterone acetate. In Medical Management of Breast Cancer. Powles, T.J. and Smith, I.E., Eds. University Press, Cambridge, U.K. pp. 95103.

12. Lanari, C., Molinolo, A.A., and Pasqualini, C.D. (1986) Induction of mammary adenocarcinomas by medroxyprogesterone acetate in BLAB/c female mice. Cancer Lett. 33, 215-223.

13. Molinolo, A.A., Lanari, C., Charreau, E.H., Sanjuan, N., and Pasqualini, C.D. (1987) Mouse mammary tumors induced by medroxyprogesterone acetate: immunohistochemistry and hormonal receptors. J. Natl. Cancer Inst. 79, 1341-1350.

14. Jordan, V.C., Ed. (1999) Tamoxifen for the Treatment and Prevention of Breast Cancer. Publishers of Oncology, Melville, NY.

15. Jordan, V.C. (2000) Antiestrogens: clinical applications of pharmacology. J. Soc. Gynecol. Invest. 7(1), S47-S48.

16. Actis, A.M., Rilo, C., Croci, M., Rivera, E., and Bergoc, R. (2000) Effect of treatment with different SERMs on uterus of mice bearing mammary experimental tumors. Medicina 60, 778.

17. Actis, A.M., Dorfman, V.B., Caruso, S.P., and Levin, E. (1998) Effects on mouse uterus of three antitumoral drugs acting upon estrogen and progesterone receptors directly and through other transductional pathways. Biochem. Pharmacol. 55, 273-278.

18. Actis, A.M., Caruso, S.P., and Levin, E. (1995) Opposite effect of a cAMP analogue on tumoral growth related to hormone dependence of a murine mammary tumor. Cancer Lett. 96, 81-85. 
19. Drabeck, K., Pesi, M., Piperski, V., Ruzdiji, S., Medi-Mijacevi, L., Pietrzkowski, Z., and Roki, L. (2000) 8-ClcAMP and thiazopurin affect vascular endothelial growth factor production and glial fibrillary acidic protein expression in human glioblastoma cells. Anticancer Drugs 11(9), 765-770.

20. Kim, S.N., Kim, S.G., Park, J.H., Lee, M.A., Park, S.D., Cho-Chung, Y.S., and Hong, S.H. (2000) Dual anticancer activity of 8-Cl-cAMP: inhibition of cell proliferation and induction of apoptotic cell death. Biochem. Biophys. Res. Commun. 273, 404-410.

21. McDaid, H.M. and Johnston, P.G. (1999) Synergistic interaction between paclitaxel and 8-chloro-adenosine 3'5'monophosphate in human ovarian carcinoma cell lines. Clin. Cancer Res. 51(1), 215-220.

22. Srivastava, R.K., Srivastava, A.R., Cho-Chung, Y.S., and Longo, D.L. (1999). Synergistic effects of retinoic acid and 8-Cl-cAMP on apoptosis require caspase-3 activation in human ovarian cancer cells. Oncogene 18(9), 17551763.

23. Srivastava, R.K., Srivastava, A.R., and Cho-Chung, Y.S. (2000) Synergistic effects of 8-Cl-cAMP and retinoic acid in the inhibition of growth and induction of apoptosis in ovarian cancer cells: induction of retinoic acid receptor beta. Mol. Cell Biochem. 204, 7-9.

This article should be referenced as follows:

Actis, A., Croci, M., Levin, E., and Bergoc, R. (2002) 8-Chloro-cAMP-related changes on mice uteri. TheScientificWorldJOURNAL 2, 1426-1432.

\section{Handling Editor:}

Joseph Chamberlain, Principal Editor for Therapeutic Drug Modeling and Pharmaceutical Sciences — domains of TheScientificWorldJOURNAL.

\section{BIOSKETCH}

Rosa Maria Bergoc is a Full Professor of Radiochemistry at the Radioisotopes Laboratory and head of Physics and Mathematics Department, School of Pharmacy and Biochemistry, Buenos Aires University. She is a Member of the National Council of Scientific and Technological Research (CONICET). Dr. Bergoc holds a Ph.D. in Biochemistry from Buenos Aires University, Argentina, with Post-doc in Radiation Protection, Triest, Italy. Her research interests include the action of insulin growth factor type-1 and histamine on growth regulation of malignant cells, and its relation with cellular radiosensibily. She has received more than twenty awards for researches on biochemistry fields and educational activities. Dr. Bergoc is a Member of the European Histamine Research Society, International Radioprotection Society, Women in Nuclear Association, New York Academy of Science, and Cancer Detection and Prevention Society, among others. 

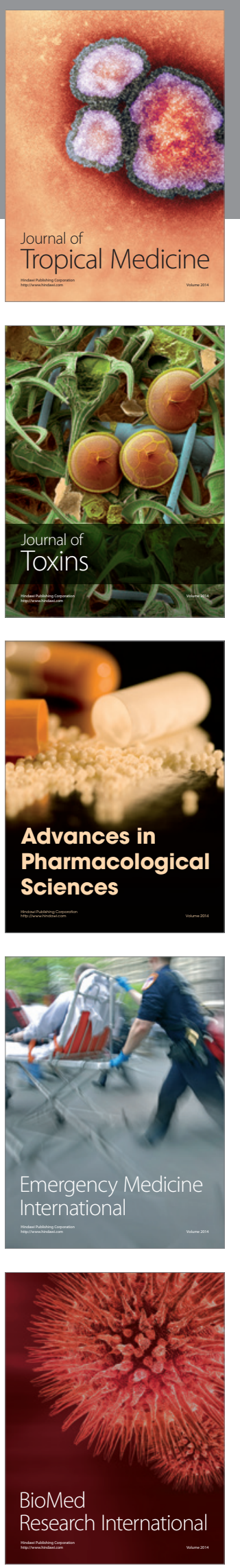


The Scientific World Journal


Submit your manuscripts at

http://www.hindawi.com
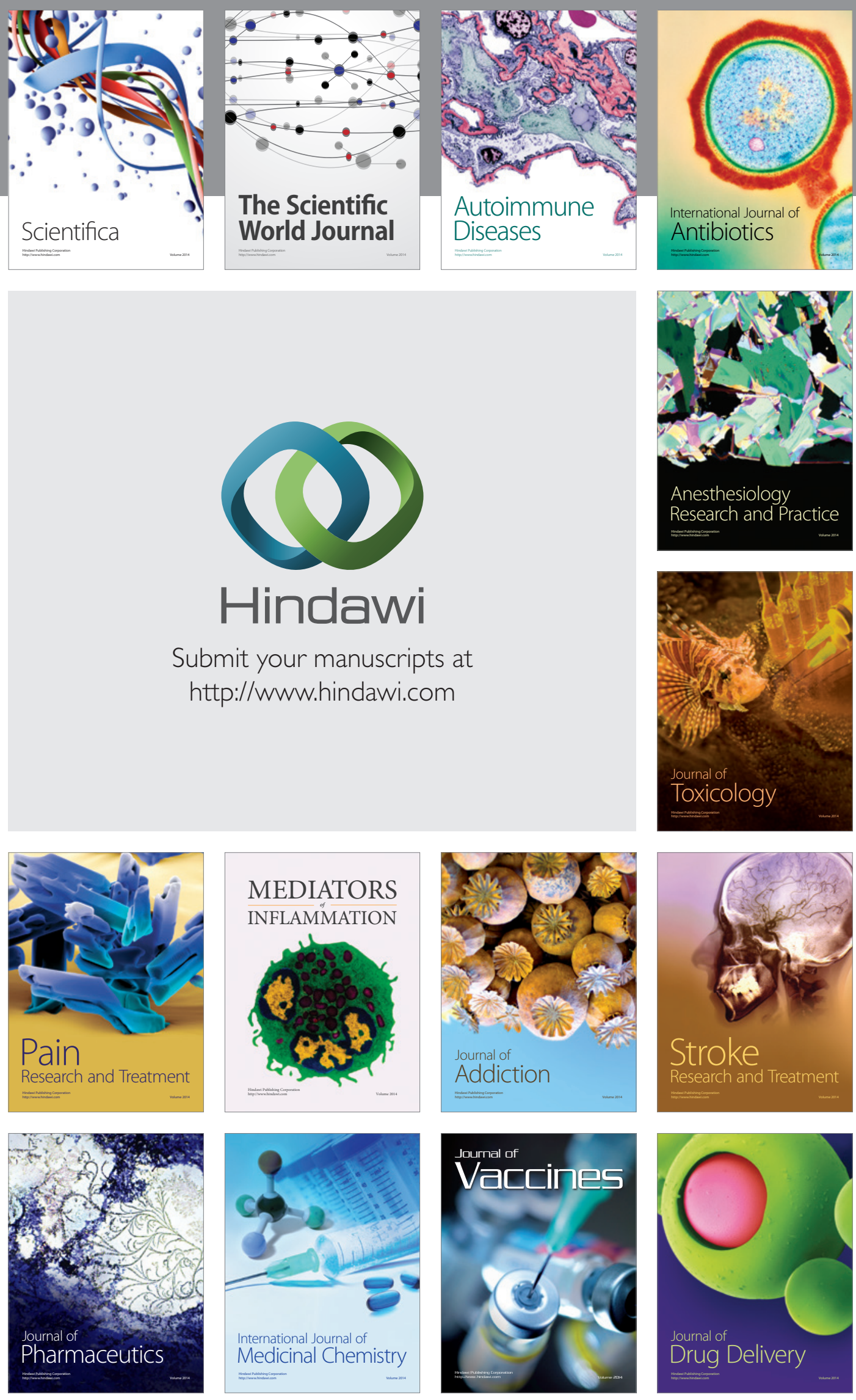